\title{
Community-Controlled Economic Development as a Strategic Vision for the Sustainable Agriculture Movement
}

\section{by Dave Campbell}

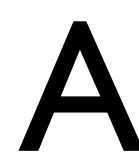

s global integration of the food and agricultural economy proceeds, so do efforts to develop local food systems attuned to the particularities of place. These countertrends will coexist, uneasily. The resulting political and economic tension provides a unique opportunity for the diverse constituencies of the sustainable agriculture movement to unite behind a common agenda. This agenda must do more than oppose the threats to sustainability posed by globalization. It also must articulate a strategic vision as compelling to the movement's community-based organizations as the notions of "free trade" and "comparative advantage" are to global corporations and their allies.

Important as they are, neither the campaign to influence the Farm Bill nor a romantic vision of bygone agrarian communities are sufficient to broaden the movement's existing political base and deepen its influence. I suggest an alternative approach: grassroots organizing guided by the vision of "community-controlled economic development." A strategy that links sustainable agriculture to community-controlled economic development is consistent with the movement's widely shared goal of promoting food and agricultural systems that are environmentally sound, economically viable, and socially just. It breaks with current movement thinking, however, in three ways: rather than considering sustainable agriculture primarily as a set of new production technologies, it defines it as an effort to assert democratic control overkey power relationships in the food and agriculture system; rather than focussing most political energy on interest group bargaining over the Farm Bill, it promotes community organizing and the mobilization of social capital; rather than emphasizing the development of agrarian-based rural communities, it seeks to foster partnerships that bridge the urban-rural interface.

This paper provides a rationale for this alternative strategy. The first section notes the compatibility between the characteristics of sustainable agriculture and emerging theories in the field of local economic development. The second section relates this body of theory to the current practices of movement organizations, using as an example the innovative networks being promoted under the banner of the California Alliance for Sustainable Agriculture (CASA). CASA, of which I am a steering committee member, is a coalition of six nonprofit and three university-based programs funded by the W.K. Kellogg Foundation's Integrated Farming Systems initiative. CASA organizations are creating models of communitybased education that help farmers, farmworkers, processors, educators, policymakers and others create communities that are prosperous, just, and democratic.

\section{SUSTAINABLE AGRICULTURE, \\ SOCIAL CAPITAL AND COMMUNITY ECONOMIC DEVELOPMENT}

Spurred by practical necessity and informed by the vision of sustainability, a new approach to local economic development has emerged gradually over the past ten to twenty years. Older approaches dependent on industrial recruitment, government grants, or unsustainable resource extraction have proven increasingly unreliable because of global economic restructuring, prolonged fiscal stress in government, and environmental crisis. Replacing them is a new emphasis on homegrown, community-based approaches that acknowledge natural constraints, develop existing assets, plug economic leaks, capture added value, and support local businesses. As Schramm (1987) notes, these emerging strategies do not ignore the power of external market forces and private corporations, but try to change the way the local economy relates to those forces. The goal is a local economy that is vital, equitable, and secure, providing challenging work and empowering all community members.

As Strange (1990) has shown, many production and marketing practices associated with sustainable agriculture are consistent with these tenets of community-controlled economic development. For example, farmers substitute skilled labour and management for purchased inputs. Diversification of crops and livestock aids soil health but also lowers economic risks to farmers and farm communities. Direct marketing and on-farm or local processing add value and 


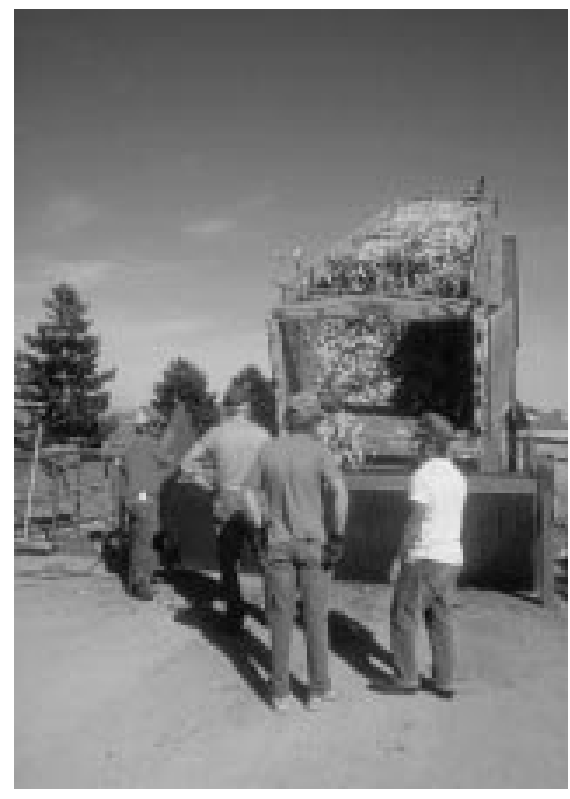

reduce economic leakage from the community. Conservation of natural capital creates economic value by maintaining the productivity of land and water resources while reducing "externalities," such as groundwater pollution or pesticide-related illness, whose costs are born by the public. Strange (1990, p. 6) concludes that:

"sustainable agriculture has local economic development benefits if it provides fuller employment of and increased return to farm resources; reduces economic "leakage" and generates increased demand for locally produced goods and services; produces increased demand for retail sales due to the multiplier effect of the previous two items; and reduces the costs which farming operations externalize to the local economy."

While farmers can act alone to achieve many of these results, all these strategies are enhanced when they collaborate with other farmers or community organizations. For example, import substitution can be speeded as farmers co-operate to devise pest control strategies specific to local conditions. Regional marketing promotions or other activities to add value can only be undertaken co-operatively, since they require levels of capital, technology, product expertise, or training that individual farmers lack. The need for collaboration has become

\section{Community-controlled economic development ... provides a conceptual umbrella under which pesticide reduction, labour, farmland protection, \& related issues are components of a single organizing effort, rather than isolated issues, each with a separate politics.}

more evident as the sustainable agriculture movement's agenda has embraced the goal of community food security. High poverty rates, hunger, and inadequate nutrition are prompting efforts to improve access to fresh, affordable, and nutritious foods, particularly among low-income families in rural and inner-city areas. This difficult work highlights the need for new coalitions that bring together rural and urban interests, such as anti-hunger organizations and farm advocates.

Such a collaborative politics must counter the strong individualist ethic in American political culture and draw instead upon the less prominent but equally persistent ethic of sharing and mutual sacrifice. Often known for their isolation and competitiveness, American farmers also have provided models of social co-operation such as barn raising and co-operative development. Such co-operation makes it more likely for local economies to be healthy. Summarizing his two decades of experience working on local economic development in both the U.S. and Canada, Perry (1987, p. 40) writes:

"For practical purposes, economic development is not the promotion of increases in gross national product or median family income or average per capita income or savings rates and investment capital or any of the usual indicators that people are accustomed to think of when they consider this idea. Instead, economic development is the creating and strengthening of new and available social tools in a community."

Perry's observation is supported by research on the role of "social capital" in fostering economic development and political democracy. Putnam (1993, p. 167) defines social capital as "features of social organization, such as trust, norms and net- works, that can improve the efficiency of society by facilitating coordinated actions." It was just this trust and co-operation that made farming communities of the past function, as farm tools and labour were borrowed reciprocally, allowing each farmer to get by with less physical or financial capital.

But Putnam does not relegate the influence of social capital to either the past or a utopian future. His research on Italy's complex, modern society concludes that the major determinant of whether a region will have a prosperous economy and healthy democracy is the presence or absence of "networks of civic engagement":

"Although we are accustomed to thinking of the state and market as alternative mechanisms for solving social problems, this history suggests that both states and markets operate more efficiently in civic settings.... Social capital, as embodied in horizontal networks of civic engagement, bolsters the performance of the polity and the economy....

Strong society, strong economy; strong society, strong state." (Putnam, 1993, pp. 176, 181)

Flora (1995, p. 2) has connected the social capital thesis with sustainable agriculture. She finds that Midwest communities with concentrated populations of farmers practicing sustainable agriculture experience an upsurge in civic activity that elevates political debate and boosts local economic development:

"A pattern of problem solving guided by norms of mutual trust and reciprocity is encouraged by the sustainable agriculture movement and the various organizations that give social expression to that movement, and this is what helps to nurture and build social capital within small, agriculturally dependent rural communities." 
Strange (1988) makes the same point negatively, observing that cutthroat competition and the absence of neighbourly co-operation undermines the pursuit of co-operative policy goals and economic outcomes.

This literature suggests that the sustainable agriculture movement might foster internal unity and create strategic allies by recasting its existing activities under the banner of community-controlled economic development. The key is articulating how each of the movement's diverse constituencies are part of a broader effort to reassert community control over the product distribution of food and fibre. This not only aligns sustainable agriculture with those promoting sustainable community development in other fields, such as energy and health care, but also with the much broader array of political forces seeking decentralization, local control, community partnerships, and home rule as alternatives to centralized bureaucracy.

Achieving the goal of community-controlled economic development will require deliberate and patient efforts to foster social capital within our communities and among movement organizations. As Schramm (1987, pp. 152-153) puts it:

"For community-based economic development to succeed, linkages among democratic organizations must be strengthened at all levels of the economy, across sectors and geographic areas, to provide increased support for local efforts and a political and economic base for confronting the power of established private and public institutions."

\section{NETWORKS LINKING SUSTAINABLE AGRICULTURE AND COMMUNITY DEVELOPMENT IN CALIFORNIA}

Are these ideas relevant to the practical work of sustainable agriculture organizations? Does "community-controlled economic development" provide an umbrella broad enough to cover the wide diversity of movement activities? Can this approach deepen our social analysis and make our politics more effective? If "community control" is the goal, who is the community and how do we foster community co-operation among people schooled primarily in individualistic pursuits?

I consider these questions by examining the recent experience of the California Alliance for Sustainable Agriculture. For the past three years, CASA's member organizations have promoted community development in successful production and marketing projects. In addition, the 9-member CASA steering committee has struggled, with less success, to create joint projects that enhance or support the work of individual organizations.

"Community" has been defined by CASA in three distinct ways: by geographic region, by commodity, and by constituency. The specific agendas of each community association have varied, the primary forms being grower information networks, marketing coalitions, agricultural planning and policy coalitions, and a farm worker support center. The following summaries describe the achievements of these community networks, their degree of success in generating social capital, and their role in promoting more self-reliant community economies. In the discussion that follows I analyze how this experience can inform three challenges facing the sustainable agriculture movement as it seeks to increase its political influence: the need to hold concentrated power accountable, to unify environmental and social agendas, and to foster strong leadership accountable to the movement's community base.

\section{GROWER INFORMATION NETWORKS}

For many California crops, farmers have developed sustainable production practices, but documentation and dissemination of these innovations proceed slowly. Cutbacks in university funding and institutional resistance to change hamper the role of Cooperative Extension in serving this purpose. Pesticide-use reports, now mandated for all fields, reveal that pesticide use remains high and that most farmland still is under traditional chemical regimes. Often, farmers adopt these regimes on the advice of pest control advisors (PCAs) who are sales agents for chemical companies. The personal relationship of farmers with these PCAs, along with strict standards mandated by processors, are major influences on farmer decision-making.

Grower information networks are an effective way to counter these institutional barriers. An example is the Integrated Pest Management (IPM) program of the LodiWoodbridge Winegrape Commission (LWWC), established in 1991 as a self-help, self-taxing marketing association. LWWC represents over 650 grower members whose production encompasses 50,000 acres of premium wine grapes, nearly $20 \%$ of California's total wine grape production. The Commission operates as a self-financed extension and pest control association, working with growers to promote sustainable production strategies that reduce conventional pesticide inputs and maintain the farmer's net income. This frees LWWC to leverage university or corporate resources without becoming a captive of their agendas.

The Commission promotes new management-intensive production regimes that add value by substituting skilled labour for purchased inputs. Initial leadership came from a small but influential group of farmers, including the owner of the largest farm in the district. These leaders saw that by making the transition to more sustainable methods they could head off regulator burdens and build a positive, "clean" image for their crops and their community. In 1991 a core group of approximately a dozen cooperators began to hold meetings twice a year to spread information about the new practices. At that time, attendance at the meetings averaged about 50 .

Five years later, LWWC boasts 120 cooperating farmers, and attendance at the biannual meetings averages 200 to 250 . In addition, all farmers in the district receive multiple notices about monthly events such as field days or breakfast meetings, and a newsletter is circulated, so that the LWWC message is delivered frequently. Along with the strength and commitment of the initial leadership, the repeated exposure to the IPM message has been important for the organization's success. Equally important are the personal relationships between 
commission staff and farmers, since personality clashes or a perception that a staff member is not knowledgeable can slow progress significantly.

LWWC finds that combining personal connections and impersonal authority is much more effective than either by itself. For example, they have sponsored neighbourhood meetings in which a dozen or so growers meet in a farmer's living room to share information. The friendly atmosphere in this setting has been highly successful in engaging new farmers. However, it builds on LWWC's earlier work to get the message out. Farmers who have read about the LWWC's efforts in trade magazines or other media are more open to making changes than if they had only a neighbour's word to go on. A big boost came recently when the Department of Pesticide Regulation (a division of the California Environmental Protection Agency) selected LWWC for California's first "IPM Innovators" award.

Another grower information network is a demonstration program initiated by the Community Alliance with Family Farmers (CAFF) to promote the adoption of locally proven, biologically based farming systems. Dubbed "BIOS: Biologically Integrated Orchard Systems," the program provides participating orchard growers with modest financial incentives and with a management team that gives technical advice geared to their particular farms. The team consists of a unique collaboration: farmers who have pioneered innovative systems of sustainable production, a pest control advisor, a Cooperative Extension farm advisor, a researcher from the University of California Sustainable Agriculture Research and Education Program, and CAFF staff. The team conducts on-site visits, on-farm monitoring, monthly field days, and skills workshops, and is available for phone consultations and trouble shooting. Participating farmers expand their management options, become more familiar with neighbouring farmers, and decrease their dependence on traditional pest control advice.

The program's successful work with groups of 20 to 30 almond and walnut grow- ers in four counties sparked California state legislation (AB 3383) in 1994 to fund projects that apply the BIOS approach to other perennial crops. The legislation marked a rare occasion in which environmentalists, regulators, mainstream and alternative farming organizations, and university administrators rallied behind the same progressive farming legislation. Collaboration enables each group to solve problems they could not solve in isolation: administrators of the Department of Pesticide Regulation see their regulatory burden lifted by offering incentives to growers rather than penalties; growers receive financial and technical help during the difficult period of transition; environmentalists get pesticide reduction without appearing hostile to farmers; and the university answers critics who want it to alter its research agenda to address problems of immediate interest to farmers. The adversarial relations and political stalemate typical in regulatory policymaking are replaced by collaboration involving government, industry, university, and public interest representatives. By the fall of 1996 , approximately 110 orchard growers will be participating in the BIOS program, a rapid expansion over the past two years. A new challenge facing the program is how to rotate new individuals onto the management teams to prevent staff burnout and to develop new leadership.

As important as "innovation" is for BIOS, so is continuity. Teamwork and new social relationships can facilitate adoption of sustainable agricultural practices, but also critical was the slower work that took place on a few innovative farms before the program was launched. A key feature of that work was the involvement of Cooperative Extension advisors who were trusted in the community and could speak in favour of the program at the initial meetings held to attract farmer participants. Having a familiar and trusted source of information made farmers more open to the innovative features of the program.

The Bio-Integral Resource Center (BIRC) has taken a different approach in promoting biologically-based IPM practices among processing tomato growers in Yolo and Solano Counties. Over a 3-year period they have enlisted 18 grower co-operators who have committed a combined 2,400 acres to IPM regimes. Potentially, up to 20,000 acres could be affected if these 18 growers made a complete transition on all their land. Unlike the Lodi case, BIRC started without a key group of farmer leaders to support the effort. They offer "Reference Field Monitoring," a grant-funded service that provides farmers with detailed, field-specific empirical information on which to base pest control decisions. To broaden the project's impact, weekly data summaries are distributed to all processing tomato growers in the region (approximately 250).

The payoff comes when farmers see that the fields managed with IPM practices can be just as productive as similar fields nearby where heavy amounts of chemicals were sprayed. As this occurs, BIRC researchers build trust with farmers and find greater receptivity from university and extension representatives, industry officials, and others. This gives them a fragile but growing legitimacy as they seek to transform the grower/PCA relationship to one in which both scientific credibility and personal interaction are vital. Instead of the traditional system, where growers rely on pest control recommendations from PCAs employed by pesticide companies, BIRC focusses on educating growers themselves to make the final pest control decisions based on quantified field data collected by independent PCAs or appropriately trained farm employees.

Efforts to build a sense of community among these Yolo and Solano County growers have proven more difficult than in Lodi. In part this is due to the highly competitive nature of the processing tomato industry, where the financial risks and rewards associated with a given year's crop are very high. Also, these tomato growers are less unified either by being close geographically or by a commitment to preserving a "small farm lifestyle." Still another barrier is the role played by tomato processors, who set extremely low pest tolerance levels, rejecting entire shipments if any tomatoes are damaged. 
Each of these information networks recasts growers: instead of passive recipients of expert advice, they become active agents with control over their access to information. For communities, the networks promote economic development by improving environmental quality, upgrading worker skill levels, enhancing a sense of identity, and decreasing dependence on distant corporations. The networks are also introducing political accountability by raising in key public forums the issue of chemical company influence over pest control. For example, BIRC, aided by other CASA organizations, organized a round table on this topic at a meeting of the Association for Applied Insect Ecology, the key professional association of most PCAs. These discussions are leading to proposals to change the way PCAs are licensed and paid, so that they are employed by farmers to give "whole farming systems" advice, rather than having their incomes tied to sales commissions.

Other social networks slow the transition to sustainable practices. Social bonds between farmers and chemical company PCAs who live in their communities, attend their churches, and send children to the same schools are one reason cited for slow adoption of IPM. The desire not to see a friend's financial situation decline may override other considerations in a farmer's mind. In other cases, peer influence can reinforce conservatism or introduce ambivalence about the economic and production data supporting IPM. It can take many years of patient organizing efforts to build sufficient trust to counter the force of existing social networks. Relationships of trust and reciprocity can be important both in hindering sustainable agriculture and in fostering it.

\section{MARKETING COALITIONS}

The future of sustainable agriculture depends on expanding the market beyond the narrow niche represented today by the organic market. Obstacles include cosmetic standards, marketing orders, price instability, and a distribution system in which farmers retain on average only $20-25 \%$ of the total value of pur- chased food. The remarkable expansion of farmers' markets in California, now numbering over 250, has enabled many small farmers using sustainable practices to remain economically viable. Farmers markets also contribute to the health of local communities by serving as incubators for other businesses. Local marketing campaigns in many California counties are expanding the demand for locally grown and processed foods by educating consumers, publishing seasonal eating guides, linking farmers with local restaurants, promoting farmer's markets, and other means.

It has been more difficult to imagine
Joaquin valley, where questions have been raised about the health and safety of farm workers and communities. Organic cotton has increased steadily over the past few years, but remains a very small fraction of the total. Since innovative cotton practices are recent, difficult technical questions are still to be worked out. The new social relationships forged by SCP make it more likely that funding and technical support will be forthcoming, since they enlarge the community of interest beyond the small group of committed farmers.

LWWC, too, has sought to build alliances that extend beyond the farming commu-

\section{When the focus is community problem-solving rather than the inherently adversarial budgetary \& regulatory processes of government, greater opportunities exist to inte- grate environmental \& social concerns.}

marketing strategies for commodities other than fresh produce. One innovative model has been pioneered by the Sustainable Cotton Project (SCP), which does research, education, and outreach to promote cotton production and processing alternatives. SCP has created a "vertical dialogue" involving all segments of the industry, including organic cotton growers, gin representatives, textile mill managers, and marketing firms. Leaders in the clothing industry are opening markets by promoting lines of organic clothing. Two widely attended transitional organic cotton conferences brought together interested parties, provided the first compilation of agricultural extension advice for organic cotton growers, and led to the creation in 1994 of the National Organic Cotton Association. The Association promotes collaborative problem-solving on production, supply, tracking, and certification issues, and develops a broad base of consumer support.

The potential benefits of this work are great, since cotton is one of California's largest and most chemically dependent crops. Heavy use of these chemicals is of particular concern in the southern San nity, primarily by educating wineries about their IPM program. Most wineries have been reluctant to give special treatment or pursue special labels for grapes produced by IPM methods, in part because consumers do not recognize the meaning of IPM in the same way they do the concept of organic. Others fear that to do so would compromise the image of wine created from conventionally grown grapes.

Whether built around a place or a commodity, marketing coalitions play a key political role by checking the power of agriprocessing and marketing firms to shape food and fibre choices. By mobilizing social capital they partially offset the powerful effects of the enormous amount of money spent each year on advertising campaigns that drive home the corporate vision of cheap, convenient food. By linking quality products to environmental, social, and economic benefits, the new marketing coalitions are getting a response from citizens tired of corporate slogans and eager for a more personal connection to what they eat and wear. They also open economic space in which local food systems become more viable. 


\section{AGRICULTURAL POLICY} AND PLANNING COALITIONS

Another critical barrier to sustainable agriculture in California is urban sprawl and development. The state has lost $15 \%$ of its farmland since 1964; conversion of prime farmland is expected to increase dramatically because of a projected tripling in the population of the 10 largest agricultural counties over the next 50 years. Since sprawl threatens all farmers, coalitionbuilding around this issue can strengthen ties between sustainable agriculture activists and mainstream farming organizations.

To spark community interest in sustaining agriculture in the face of development, the University of California at Santa Cruz's Center for Agroecology and Sustainable Food Systems (CASFS) created the Agriculture and Community Project (AgComm). AgComm engages in applied research and education in collaboration with the local community, such as public forums on the past, present, and future of agriculture around Monterey Bay.

The project began in 1992 by pulling together a 9-person planning committee representing diverse community stakeholders: Farm Bureau, Cooperative Extension, a local real estate agent, a mayor, a city council member, a church representative, a farmer, a community organizer, and an interested community member. This group met once a month for five months, then less frequently for the next year. These initial discussions stalled when the project staff person left the university, but they resumed a short time later when a grant made it possible to hire a replacement. Over a 3-year period beginning in 1993, many public meetings were held, the largest of which attracted 120 participants to a session in which community members established priorities for research and community action. Farmland protection emerged as a key issue, and AgComm followed up by conducting research, organizing a tour of nearby counties with progressive farmland protection policies, and advising the Agricultural Policy Advisory Commission to the Board of Supervisors regarding agriculture on the urban edge.
While these efforts have yet to produce specific policy changes, they have built important relationships and raised community awareness of farmland issues. The AgComm staff person began regularly attending Farm Bureau meetings, helping to improve CASFS's image with local farmers. Maintaining these community relationships has become a more integral part of how CASES sees its mission. Teaming up with Cooperative Extension, AgComm held a National Issues Forum on the topic of farmland protection that attracted 50 participants, including most of the community's influential power holders. A group of 25 to 30 forum participants still meets regularly, despite the end of the initial grant to AgComm and the need to rely on volunteer support for staffing and facilitation. The commitment of this group to carry on without paid staff, and the strength and diversity of its membership suggest that the slow process of coalition building is beginning to generate increased social capital. Whether this will lead to tangible policy changes remains to be seen.

\section{FARMWORKER SUPPORT CENTER}

Inflation-adjusted wage rates for California farm workers have fallen by $10 \%$ over the last decade, and working conditions are poorer than in most other industries. Unable to obtain secure, year-round employment at living wages, farm workers and their families often require support from public service budgets and are seen by many as a burden on the community. The farm worker support network initiated in 1985 at the Rural Development Center (RDC) in Salinas demonstrates that the farm labour force could just as easily be seen as an underutilized community asset awaiting proper development.

The RDC combines aspects of a grower information network, marketing coalition, and training program, all focussed on the goal of establishing farm worker families as independent farmers. The RDC promotes self-reliance by helping people gain skills and experience they need for starting their own farming operations or seeking more stable employment. Through a collaborative relationship with the University of California, the Center conducts research and outreach on sustainable production practices. For its farm worker constituency, whose experience is predominately with conventional agriculture, the education opens the possibility of a different way of farming. A recent survey documented that $78 \%$ of the 60 families completing the center's 3-year training program now farm on their own as their principal livelihood.

The RDC has become more than just a support network for farmer-to-farmer information exchange. It actively integrates families into its work. For example, the training program involves not only the farm worker, but also spouses and children. A recently started youth garden project has brought Salinas-area students to the RDC site for training and field projects. The RDC leadership is committed to expanding the web of community connections, especially those involving women, children, and youth.

\section{DISCUSSION}

To reach its multifaceted goals, the sustainable agriculture movement must be more effective in holding concentrated power accountable, must unify its environmental and social agendas, and must foster and sustain leadership that combines sound analysis, political savvy, and sensitivity to its community base. The CASA projects just described show how a political strategy emphasizing a vision of community-controlled economic development might significantly aid the movement in meeting these difficult challenges.

\section{Holding power accountable}

Paarlberg (1995) has argued that the fundamental cause of resource abuse in agriculture is abuse of power, rooted in relationships that allow the few to pursue gain without accountability to the many. Advocates of sustainable agriculture have challenged these relationships by organizing to influence the Farm Bill and other public policies at the national and state levels. There are problems, however, with making this the exclusive or primary political strategy. The decision-making arenas in which these battles are fought are well defended 


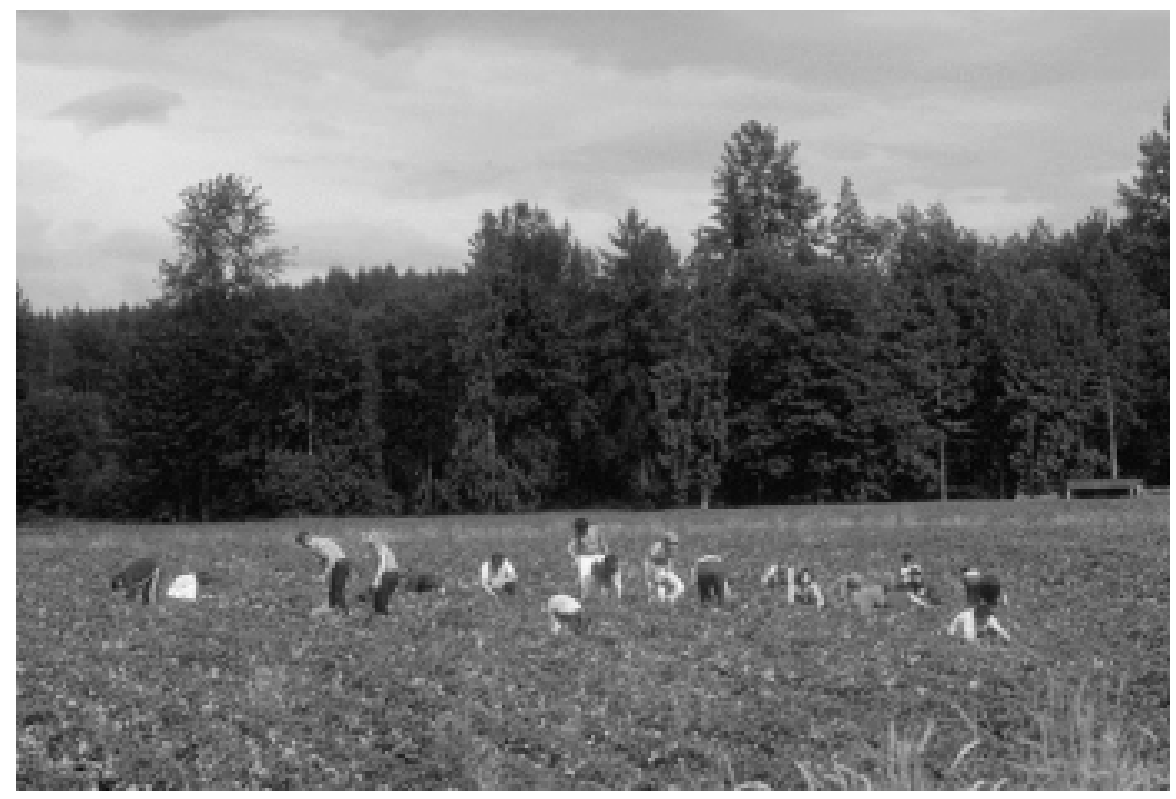

by established interests, making organizing efforts costly, difficult, and occasionally futile. The currencies of power that matter in these arenas, money and prestige (often measured by the perception that one's business is critical to the health of the Gross National Product), are not movement strengths.

By contrast, CASA's networks employ community organizing strategies to alter power, drawing on resources in ample supply: credibility, personal relationships, and a shared commitment to place. The most successful organizing efforts nurture and exploit each of these strengths in several ways: by developing analytical capabilities that make them a regular and trusted source of information; by taking the time to build personal relationships, rather than imposing a set program of ideas to be disseminated impersonally; and by identifying common interests and consensus approaches whenever possible.

While focussing few resources and little energy on explicit efforts to "change public policy," CASA organizations nevertheless challenge key power relationships. Grower information networks free farmers from dependence on "experts" with strong ties to agribusiness, and link them instead to neighbouring farmers and to sources of technical advice that they themselves control. Marketing coalitions carve out niches in which farmers and citizens can be linked more directly and deliberately, allowing social values to take their rightful place alongside commercial concerns. Agricultural planning and policy coalitions raise community awareness and check the power of developers over local decisionmakers. Farmworker support networks empower those who are least powerful in the current system, changing them from perceived liabilities to community assets.

The effectiveness of these efforts can be enhanced if they become less isolated. Greater cohesiveness would enable organizations to learn from one another's successes and failures, avoid duplication of efforts, forge strategic alliances, and provide a grassroots base for changing public policy. Yet CASA has struggled to identify collaborative projects to achieve these ends. In part, this was due to the difficult nature of the collaboration, which brought together groups with pre-existing conflicts and with accountability to different and sometimes directly conflicting interests and constituents. But it also was due to lack of a shared strategic vision that could integrate these constituencies behind a common agenda. The promise of community-controlled economic development is that it provides a conceptual umbrella under which pesticide reduction, labour, farmland protection, and related issues are components of a single
Environmental \& social concerns are not always easily resolved at the community level. But when stakeholders representing these interests are brought together in contexts that highlight their common interest in a healthy community, consensus on concrete initiatives is made more probable.

organizing effort, rather than isolated issues, each with a separate politics.

\section{Unifying environmental and social agendas}

Policy-making processes at the national level tend to separate sustainable agriculture's environmental and social agendas, fitting them into distinct and often conflicting niches. The resulting policies, along with competitive market pressures, have made input substitution and improved production techniques a much higher priority than improving labour conditions, preserving farmland, eradicating hunger, or aiding rural communities. In this political setting, the effort to address social issues is often viewed as counterproductive, since it threatens farm profits and weakens political support for environmental policies. When the focus is community problem-solving rather than the inherently adversarial budgetary and regulatory processes of government, greater opportunities exist to integrate environmental and social concerns. A shared commitment to a place and the expectation of continuing encounters tend to check behaviour that deviates from shared community interests and to subsume separate issues under a broader concern for the community's welfare.

In its initial deliberations about how to allocate resources, CASA's steering committee found it difficult to reconcile the competing agendas of its member organizations, which ranged from outspoken advocates of social issues to mainstream farm- 
ers interested primarily in pesticide reduction. Early meetings were conducted in the spirit of a formal budgetary hearing. But as trust developed during three years of monthly meetings and other joint activities, bridges were slowly built. Discussions between the LWWC's executive director and other members of the CASA steering committee led LWWC to hold IPM training sessions for farm workers, which has increased their skills and earning potential while also benefiting employers. AgComm's work on farmland protection gave greater credibility and visibility to its report on farm worker housing and to CASES's research on organic agriculture. The Sustainable Agriculture Research and Education Program worked with other CASA organizations to link farmers with low-income residents under the rubric of "community food security." By the end of the grant, the steering committee made a unanimous decision to allocate scarce funds to the RDC for minority outreach programs. The point is not that environmental and social concerns are always easily resolved at the community level. But when stakeholders representing these interests are brought together in contexts that highlight their common interest in a healthy community, consensus on concrete initiatives is made more probable.

Fostering collaborative, community-based leadership

Integral to the success of each of the CASA networks are creative and hardworking leaders. The networks train new movement leaders and strengthen the influence of existing ones. For example, the RDC currently is directed by one of its former students, who

\section{If it is to build on its achievements \& advance to a new level of unity \& influence, the sustainable agriculture movement must transcend the limits of interest-group environmentalism.... Successful democratic movements create institutions within which prevailing social ideas \& power relations are called into question \& new initiatives forged.}

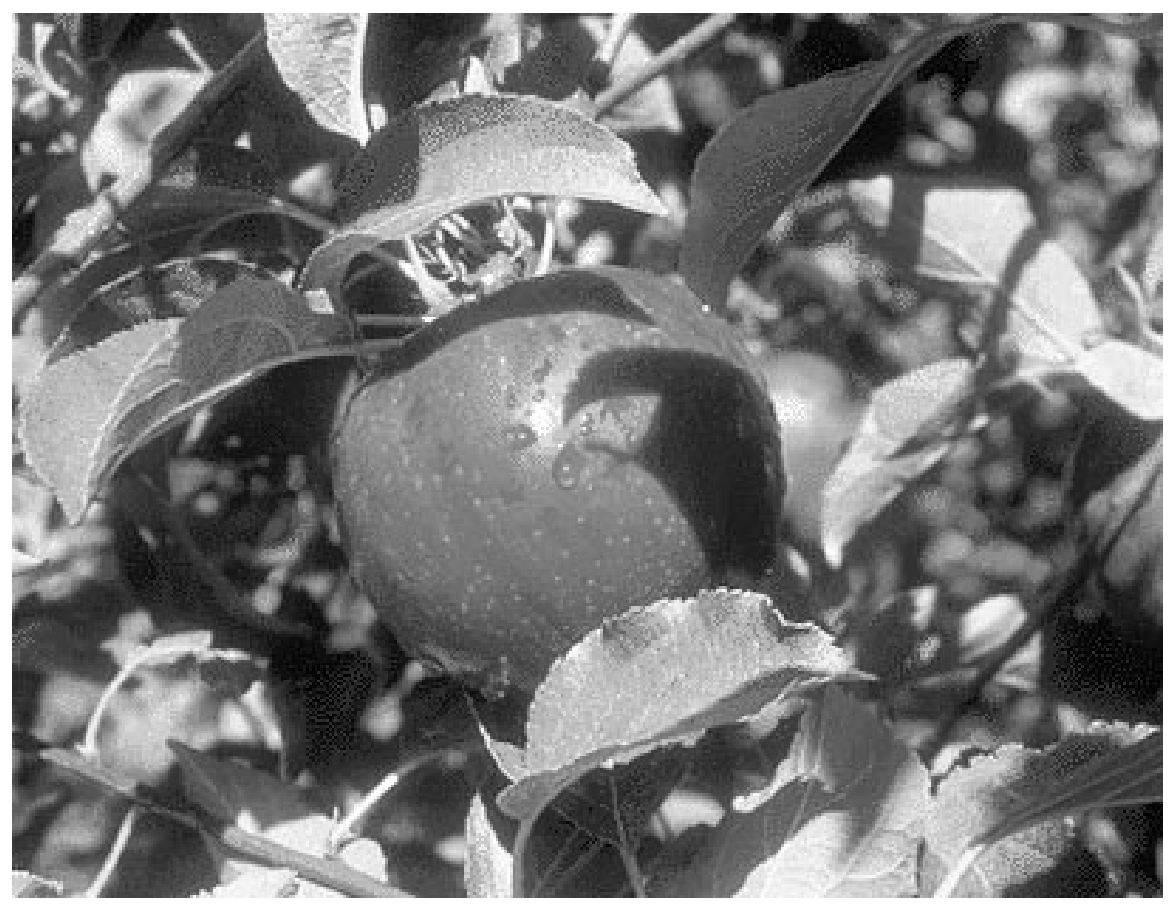

now serves on important state and national boards and policy committees. Lodi grape growers have developed a strong sense of cohesion and have enhanced their community's sense of identity. Because local political leaders view them as "doing the right thing" regarding chemical use at the urban interface, regulatory issues such as water quality are resolved with less time and difficulty. CAFF and BIRC leaders, once considered on the "environmental fringe," have become part of an established network of university and governmental representatives. A series of leadership training seminars sponsored by CASES has extended the CASA experience to emerging community-based leaders.

But these successes have yet to translate into a common, shared leadership that can overcome the competing agendas and turf battles that still divide California's sustainable agriculture organizations. Despite having ample funds to support a major collaboration, CASA often failed to find consensus, and resorted to "dividing the pie" among participating organizations. This tendency diminished gradually over a 3-year period, as experience in working together led to greater trust and formation of "mini-collaborations" to work on projects of common interest. By the third year of the collaboration, after gaining experience in tackling tough issues and developing skills in group process, the steering committee finally agreed on a joint project: creating a "Call to Action" for the California sustainable agriculture movement. This document will be useful to heighten awareness of the need for movement organizations to collaborate on policy goals, but it falls short of outlining a coherent strategy for how this will be accomplished.

\section{CONCLUSIONS}

If it is to build on its achievements and advance to a new level of unity and influence, the sustainable agriculture movement must transcend the limits of interest-group environmentalism. Its new form will be more akin to the recurring populist insurgencies in which farmers have challenged elite abuse of power and the hold of industrial values over American culture. This transformation will require a "sociological 
imagination" comparable to the imaginative production practices of creative farmers. As Mills (1959) describes it, the fruit of this imagination is the ability to turn private "troubles" borne individually into public "issues" advanced by groups that define common problems and shared interests. Successful democratic movements create institutions within which prevailing social ideas and power relations are called into question and new initiatives forged.

The CASA experience shows that the sustainable agriculture movement is creating these "free spaces." On the other hand, it has yet to produce a coherent strategy that articulates in simple terms what the movement's diverse community-based organizations have in common and why they should work together at the local, regional, state, or national levels. The concept of community-controlled economic development can unite the movement around building community food systems that nurture co-operative relationships while enhancing economic self-reliance. The result can be a more cohesive and compelling political strategy, one that establishes sustainable agriculture as a vital ally of communities battling economic dependence and of citizens seeking satisfying face-to-face encounters where shared problems are identified and solutions discovered. In our increasingly cynical age, providing such encounters contributes not merely to the movement's explicitly stated goals, but to the common quest for vital civic life.so

\section{SELECT REFERENCES}

This article was originally published in American Journal of Alternative Agriculture (1997) 12,1:37-44. Reprinted (with minor abridgement) by permission. For a copy of the original article, complete with references, contact the American Journal of Alternative Agriculture (tel) 703-525-9430 ext. 675.

Ayres, J., R. Cole, C. Hein, S. Huntington, W. Kobberdahl, W. Leonard, and D. Zetocha. 1990. Take Charge: Economic Development in Small Communities. North Central Regional Center for Rural Development, Ames, Iowa.
Feenstra, G. 1997. "Local food systems and sustainable communities." American Journal of Alternative Agriculture, 12:28-36.

Flora, C.B. 1995. "Social capital and sustainability: Agriculture and communities in the great plains and corn belt." Research in Rural Sociology and Development: A Research Annual. 6: 227-246.

Kemmis, D. 1990. Community and the Politics of Place. Univ. of Oklahoma Press, Norman.

Lyson, T.A., Gillespie, G.W. Jr., and Hilchey, D. 1995. "Farmers' markets and the local community: Bridging the formal and informal economy." American Journal of Alternative Agriculture, 10:108-113. Mills, C.W. 1959. The Sociological Imagination. Oxford Univ. Press, Oxford, England.

Paarlberg, R. 1995. "Environmental damage in world agriculture: A deeper political explanation.” Discussion Paper No. 2. Center For Agriculture, Food and Environment, School of Nutrition, Tufts Univ., Medford, Massachusetts.

Perry, S. 1987. Communities on the Way: Rebuilding Local Economies in the United States and Canada. State Univ. of New York Press, Albany.

Putnam, R.D. 1993. Making Democracy Work: Civic Traditions in Modern Italy. Princeton Univ. Press, Princeton, New Jersey.

Ritchie, M. 1993. "Agricultural trade liberalization: Implications for sustainable agriculture," in The Case Against Free Trade: GATT, NAFTA and the Globalization of Corporate Power. Earth Island Press, San Francisco, Ca. pp. 163-194.

Schramm, R. 1987. "Local, regional, and national strategies," in S.T. Bruyn and J. Meehan (eds). Beyond the Market and the State: New Directions in Community Development. Temple Univ. Press, Philadelphia, Pennsylvania.

Strange, M. 1990. Rural economic development and sustainable agriculture. Center for Rural Affairs, Walthill, Nebraska.

Thomas, M.G. 1990. Recouple - Natural Resource Strategies for Rural Economic Development. Midwest Research Institute, Kansas City, Missouri.
DAVE CAMPBELL is a political scientist who serves as a Cooperative Extension Specialist in Community Studies and as Director of the California Communities Program (CCP) in the Human and Community Development Department at the University of California at Davis. His research examines the intersection between public policy and community development processes at the local level, focussing on governance, civic engagement, citizenship, and economic development. Between 1990 and 1996 he served as community development and public policy analyst for the University of California Sustainable Agriculture Research and Education Program. In that role he served on the steering committee of the California Alliance for Sustainable Agriculture (now defunct), a collaboration of major sustainable agriculture organizations in the state funded by the W.K. Kellogg Foundation's Integrated Farming Systems Initiative. Dave expresses his thanks to colleagues on the CASA steering committee, who provided detailed information and supported his research. Contact Dave Campbell at (tel) 530-754-4328, (e-mail) dave.c.campbell@ucdavis.edu 